\title{
Meios digitais participativos e economia criativa: uma exploração das plataformas brasileiras de crowdfunding
}

\section{César Steffen}

Doutor; Centro Universitário Ritter dos Reis

cesar@steffen.net.br

\section{Resumo}

Com a Internet surge o crowdfunding, sistema de financiamento coletivo que permite que pessoas de toda a rede efetuem contribuições para viabilizar um projeto. O Brasil já conta com mais de 59 plataformas com variados objetivos e formas de atuação. Neste artigo serão analisados o crowdfunding e as plataformas brasileiras, seus formatos e regras, de forma a observar suas características e especificidades. Duas plataformas com maior quantidade de projetos foram selecionadas para um aprofundamento da descrição e análise.

\section{Palavras-chave}

Crowdfunding. Meios digitais participativos. Economia Criativa. Projetos.

\section{Introdução}

O espaço de fomento ao desenvolvimento de novas ideias e novos projetos é composto por um amplo e variado ambiente, onde coexistem e atuam atores de diversos campos e focos, como universidades, incubadoras de empresas, aceleradores de negócios, investidores e agências de fomento, empreendedores e bancos, dentre vários outros. 0 crowdfunding, modalidade de financiamento coletivo surgido na Internet, talvez seja a maior e mais inovadora novidade surgida neste contexto.

Nestas plataformas, usuários da internet são convidados, através de suas redes de relacionamento, a apoiar financeiramente projetos dos mais variados focos e objetivos, que devem obrigatoriamente apresentar algum tipo de recompensa aos apoiadores e podem ser desenvolvidos se obtiverem os recursos necessários dentro do tempo previsto. 
Desde apoio a projetos culturais e eventos, passando por ações sociais, até microfinanciamento para pequenos empreendedores, o financiamento coletivo através das plataformas de crowdfunding abrange - ou pode abranger - uma infinidade de ações que variam conforme o foco de interesse dos promotores da plataforma e os projetos que são aprovados para buscar o apoio das pessoas através da Internet (COCATE; PERNISA JÚNIOR, 2012).

Assim, este estudo objetiva apresentar uma exploração e análise das plataformas de crowdfunding brasileiras, observando suas características, formas de atuação e projetos nelas disponibilizados, traçando assim um panorama do financiamento coletivo no Brasil. Busca-se desenhar um quadro das ações e atividades das plataformas de crowdfunding em atuação no país na atualidade, de forma a compreender suas características, formatos, estratégias.

\section{Comentário metodológico}

Para cumprir tais objetivos, foi utilizada a metodologia do estudo de caso descritivo. Yin (2010) e Stake (1999), dentre outros, colocam que um estudo de caso pode ter algo, um objeto ou situação, bem definido ou não, partindo de ou focando em situações concretas ou abstratas somente pela observação. Como o crowdfunding é um fenômeno novo, recente, com processos ainda em definição e também altamente mutáveis, optou-se pelo instrumental ofertado por esta metodologia, não somente levando em conta a novidade representada pelo fenômeno do crowdfunding e pela amplitude e flexibilidade na análise ofertada por tal instrumento, mas principalmente pela possibilidade de descrever o contexto de surgimento e desenvolvimento desta novidade e de avaliar de que forma se apresenta, se comporta.

Assim, inicialmente será efetuada uma breve, porém focada, revisão bibliográfica sobre os temas da economia criativa e do financiamento coletivo através das redes digitais. Desta forma, será construída a base teórico-conceitual necessária para caracterizar e compreender um fenômeno que ainda carece de estudos acadêmicos aprofundados.

No início do período da pesquisa que gerou este artigo, no ano de 2012, foi possível identificar 66 plataformas de crowdfunding, sendo que, dentre estas, 59 apresentaram atividades efetivas, pois muitas ou não estavam mais disponíveis, ou sequer apresentavam qualquer projeto disponibilizado. Tendo estas 59 em foco, foi possível, ao longo do segundo semestre do ano de 2013, observar os mais diversificados objetivos, abrangendo desde 
produção cultural, shows e espetáculos, até financiamento de projetos sociais, de empresas startups e até mesmo apoio para animais carentes ou para o pagamento de dívidas de clubes de futebol.

Apresenta-se, assim, a necessidade de seleção e de classificação destas plataformas. Dessa forma, estas serão primeiramente classificadas seguindo os modelos de recompensa propostos pelo National Endowment for the Arts (NESTA, 2012), ou Fundo Nacional de Artes, em uma tradução livre - para fins de observação e quantificação do modelo de operação. Para compreensão, o NESTA - organização de apoio à arte, à inovação e negócios nestas áreas, sediada no Reino Unido - propõe quatro modelos de recompensa específicos, sendo estes de Doação, de Recompensa, de Concessão de Empréstimos e de Investimento. Tais modelos permitem observar o tipo de benefício ofertado aos contribuintes dos projetos, elencando aquilo que pode ser compreendido como importante mecanismo de atração, atrás apenas do objeto do projeto proposto.

Em seguida, será efetuada uma segunda classificação conforme o objeto de atuação e os objetivos declarados e identificados nos sites das respectivas plataformas, para fins da extração específica dos objetos de análise e descrição. A classificação será organizada, conforme pré-observação realizada via Internet no Brasil e no exterior, em plataformas de:

a) Projetos Culturais: aqueles que focam na produção e circulação de produtos culturais, como espetáculos, fotografia, cinema e temas relacionados a estes;

b) Projetos Sociais: que estabelecem foco no apoio a causas sociais, como ONG's, reformas de associações culturais, incentivo a adoção de animais, etc.;

c) Projetos Diversificados: plataformas que não tenham um formato específico e definido, mas que aceitem projetos com diversificados focos;

d) Empreendedorismo: plataformas de captação de apoio para empreendedores tradicionais que precisem de apoio financeiro ou estratégico;

e) Software: plataformas de apoio ao desenvolvimento de sistemas informáticos;

f) StartUps: apoio ao desenvolvimento de empresas nascentes;

g) Projetos gerais: que não se encaixam nos critérios anteriores, como a já citada plataforma para auxílio ao pagamento da dívida do Clube de Futebol Vasco da Gama.

Efetuado o levantamento e classificação, e levando em conta as limitações de espaço deste estudo, serão selecionadas para análise as plataformas com mais tempo de operação e as que apresentarem maior quantidade de projetos ativos, passíveis de apoio ou já apoiados. 
No caso de serem encontradas plataformas com quantidades equivalentes de projetos, será selecionada a que tiver maior tempo de atividade. Como este estudo apresenta limites naturais de espaço, serão apresentadas somente as duas que apresentarem mais relevância no cruzamento dos dois critérios.

Assim, primeiramente serão descritos os objetivos de cada plataforma conforme as informações constantes nos respectivos sites. Em seguida, observaremos os projetos constantes nos mesmos, uma vez que as plataformas são apenas intermediadores da relação entre empreendedores e apoiadores.

Desta forma, no tocante aos projetos, focaremos nos que constam nas páginas iniciais, não somente por tenderem a ser os mais recentes, mas também por estarem em maior exposição no momento, logo tendo maior visibilidade.

Para iniciar, tratamos de apresentar uma breve, porém necessária, revisão dos conceitos de economia criativa e de crowdfunding, que serão articulados quando da apresentação e análise das plataformas selecionadas.

\section{Economia e indústria criativas}

As indústrias criativas, como o conceito deixa transpor, são aquelas que apresentam um alto grau de inovação e de mudança de paradigmas econômicos em sua formatação, mostrando-se como um setor em amplo crescimento no Brasil e com excelentes oportunidades para a geração de novos negócios. Para colocar um termo de comparação e medida, em relatório de 2010, a Conferência das Nações Unidas para o Comércio e o Desenvolvimento, ou United Nations Conference on Trade and Development (UNCTAD), observou uma queda de $12 \%$ no comércio global no ano de 2008. Em sentido contrário a esta realidade, o setor de serviços e bens de economia criativa cresceu mais de $14 \%$ (UNCTAD, 2008).

Entre os países com maior atuação no setor de economia e indústrias criativas, estão China, Estados Unidos e Alemanha. O Brasil, apesar de crescer a ponto de se tornar a quinta maior economia do mundo, não consta sequer entre os 20 maiores produtores em economia criativa no mundo.

O conceito de economia criativa - ainda um tanto impreciso academicamente, até por sua natureza recente - tem sua origem no discurso Creative Nation (nação criativa) proferido pelo primeiro-ministro australiano em 1994, onde argumentava a necessidade de se observar as oportunidades geradas pela globalização e pelas novas tecnologias digitais 
como forma de gerar novas oportunidades e estimular a criatividade das pessoas, formando um movimento de desenvolvimento positivo para seu país.

Esta ideia ganhou força a partir de 1997, quando o então primeiro-ministro Britânico Tony Blair criou uma força tarefa abrangendo vários setores da sociedade com o objetivo de analisar e observar as novas tendências de mercado e as vantagens competitivas do Reino Unido para fazer frente a crescente concorrência internacional. Deste trabalho, a força tarefa destacou como oportunidades relevantes as áreas da cultura, desenvolvimento, turismo e educação, dentre outras.

A economia criativa e suas indústrias começam, assim, a se mostrar não só como conceito ou ideia, mas como oportunidade real de geração de novos negócios. Reconhecendo a importância e o peso da originalidade e dos aspectos intangíveis para a geração de valor, a economia criativa toma da economia da cultura a valorização do autêntico, do único e do intangível, e empresta da economia do conhecimento a ênfase no tripé tecnologiaqualificação do trabalho-propriedade intelectual.

Assim, podemos compreender as indústrias criativas como setores econômicos específicos, baseados na vocação, na cultura e nos valores locais, bem como na inovação, capazes de gerar renda, empregos, tributos e divisas. Abrangem, assim, não somente as empresas com foco em economia criativa, mas também as correlações que estas estabelecem com os demais setores da economia - como o design de um produto frente à produção do mesmo, a arquitetura frente à construção civil, a moda em relação à indústria têxtil e ao varejo de vestuário, e assim por diante.

No Brasil, em 2011, as Indústrias Criativas contemplavam cerca de 243 mil empresas, que geraram em torno de 110 bilhões de reais em rendimentos, equivalente a cerca de 2,7\% do PIB nacional, contra 5,8\% no Reino Unido e 3,3\% nos Estados Unidos (FIRJAN, 2012).

Conforme pesquisa realizada no ano de 2012 pela Federação das Indústrias do Rio de Janeiro (FIRJAN, 2012), os setores de Economia Criativa geraram 810 mil empregos formais e diretos no Brasil, representando pouco mais de 1,7\% do total de mão-de-obra empregada no país. Moda e Arquitetura destacam-se neste aspecto, sendo que somente o primeiro representa quase $30 \%$ do total de trabalhadores envolvidos em economia criativa no país.

Ampliando o olhar e incluindo setores relacionados e de apoio, observamos uma mudança de cenário, pois os números sobem para 11 milhões de trabalhadores envolvidos nas 184 atividades, representado 24\% dos trabalhadores formais em todo o país. Os salários dos trabalhadores no setor de Economia Criativa também são maiores. Enquanto a média de 
remuneração mensal de um trabalhador brasileiro em 2011 era $R \$ 1.588,00$, no setor de economia criativa esta média sobe quase três vezes (FIRJAN, 2012).

Muitas oportunidades dentro deste campo surgem em pequenas ações e em micro empreendimentos, que se viabilizam através da rede e de ações de inteligência coletiva. Uma das formas de financiamento que surgiu recentemente e que permite a empreendedores e inovadores buscar caminhos alternativos para a viabilização de seus projetos é o crowdfunding.

\section{Apresentando o crowdfunding}

O crowdfunding, ou financiamento coletivo, numa tradução livre adotada pelos brasileiros, tem sua origem no crowdsourcing, uma forma de desenvolver soluções e resolver problemas de forma coletiva usando os recursos da Internet para aproximar pessoas que, fisicamente distantes, podem atuar em conjunto. 0 desenvolvimento do sistema LINUX talvez seja um dos melhores exemplos de crowdsourcing aplicado ao desenvolvimento de soluções, mas este modelo possa ser aplicado a qualquer situação ou problema. Interessante recordar também que o programa SETI - Search for ExtraTerrestrial Inteligence, pesquisa por inteligência extraterrestre, numa tradução livre - lançou mão do crowdsourcing para o processamento de informações captadas, usando protetores de tela que, quando acionados nos computadores pessoais das pessoas, utilizavam o poder de processamento para os cálculos necessários.

Conforme Steinberg (2012), o crowdfunding é definido como o processo de utilizar as redes digitais para pedir doações ao público em geral, de forma a viabilizar novos empreendimentos. O termo crowdfunding surge da fusão da expressão "crowd", grupo, multidão, e "funding", financiamento. Ou seja, na raiz da expressão vemos uma forma de financiamento que se origina na multidão, num grande grupo que se une para financiar algo. Fruto da era das redes digitais de interação (FELINTO, 2012) e da "inteligência coletiva", que possibilita a aproximação e interação entre pessoas com um objetivo ou causa comum que podem agir em sinergia (LÉVY, 2007), o crowdfunding surge e se desenvolve como uma forma de captação de recursos para projetos em várias áreas (COCATE; PERNISA JÚNIOR, 2012).

Nas plataformas de crowdfunding, pessoas ou grupos interessados em desenvolver determinados projetos os propõem e divulgam, buscando através da rede digital o apoio financeiro para a sua viabilização num determinado espaço de tempo (BELLEFLAMME; 
LAMBERT; SCHWIENBACHER, 2011). Se alcançado o valor solicitado no prazo previsto, o projeto recebe o apoio e pode ser executado. Se não, os apoiadores recebem os valores de volta.

Uma característica marcante dos projetos de crowdfunding é que os contribuintes recebem retorno do apoio, mas este retorno nunca é financeiro, e pode variar conforme o valor doado e as características da proposta (RONCOLATO, 2011). Ingressos gratuitos, citação de nomes nos créditos ou exemplares do produto são alguns dos possíveis - e observados - formatos de recompensa.

0 tema chegou às manchetes em 2008 com o financiamento da campanha do então candidato à presidência norte-americana Barack Obama (MANGOLD; FAULDS, 2009). Já no ano seguinte, 2009, notamos a primeira experiência de financiamento de projetos com outros focos, com o surgimento do site norte-americano Kickstarter, onde artistas, produtores culturais e pessoas de áreas variadas podiam apresentar um projeto para financiamento. As condições básicas exigiam que o projeto tivesse um valor preciso para realização, um prazo de execução e recompensas não financeiras para os doadores na rede.

Nestes pontos reside a essência do processo de crowdfunding. Os projetos necessitam ter um foco específico, devem ser realizados por pessoas com experiência e capacidade de construir o que propõem, obrigatoriamente precisam ter prazos de execução com início e fim, também oferecer recompensas não financeiras para as pessoas que doarem recursos (BELLEFLAMME; LAMBERT; SCHWIENBACHER, 2011) e, acima de tudo, devem ser capazes de atrair a atenção e apoio na rede, de forma a transformar esta atenção em recursos doados.

De acordo com observações empíricas, assumimos que a natureza desses benefícios para a comunidade varia de acordo com a forma de crowdfunding adotada: benefícios comunitários estão vinculados à experiência de consumo no âmbito de um mecanismo de pré-encomenda, e com a experiência de investimento no âmbito de um mecanismo de partilha de produtos e experiências. (BELLEFLAMME; LAMBERT; SCHWIENBACHER, 2014, p. 3, tradução nossa ${ }^{1}$ ).

Conforme relatório de pesquisa publicado por NESTA (2012), existem quatro tipos distintos de modelos de recompensa em crowdfunding:

\footnotetext{
${ }^{1}$ No original: "In accordance with empirical observations, we assume that the nature of these community benets varies with the form of crowdfunding: community benets are tied to the consumption experience under a pre-ordering mechanism, and to the investment experience under a pro-sharing mechanism". (BELLEFLAMME; LAMBERT; SCHWIENBACHER, 2014, p. 3).
} 
a) Modelo de Doação: voltado mais especificamente para a arrecadação de dinheiro para projetos com fins sociais e de caridade, modelo onde os apoiadores doam porque desejam e não esperam algo em troca;

b) Modelo de Recompensa: mais comum e mais presente nas plataformas atuais, este modelo tem como fundamento a oferta de recompensas não financeiras em troca de doações, e normalmente a recompensa é proporcional ao capital ofertado como apoio;

c) Modelo de Concessão de Empréstimos: neste modelo, pessoas que tenham interesse em obter empréstimo são colocadas em contato com pessoas que possam conceder tais empréstimos, sem a interferência de bancos ou instituições financeiras.

d) Modelo de Investimento: surgida após a falência de vários plataformas de investimentos após a crise de 2008 nos Estados Unidos, este modelo tem foco no investimento em capital próprio ou partilha de receitas em empresas ou projetos, sendo uma excelente forma para financiar startups, pois os investidores tem participação nos lucros.

Importante esclarecer que a recompensa não financeira aos apoiadores se sustenta na ideia de que a doação deve ser em prol do projeto, da ideia e sua execução, e não em troca de lucro ou qualquer outro objetivo financeiro.

Assim, a Internet acelera e simplifica o processo de busca por grupos de financiadores potenciais, os quais podem usar o crowdfunding para ingressar nas atividades mais inesperadas de nossa cultura, como a música e o cinema (HOWE, 2009).

A partir da experiência do Kickstarter, que já mobilizou mais de 100 milhões de dólares em projetos e doações, várias outras plataformas surgiram, com foco bastante variado, como teatro, exposições, e até mesmo shows de artistas consagrados, que são viabilizados com a compra antecipada de ingressos na Internet, como a plataforma brasileira "Showzasso". A primeira experiência brasileira que se tem conhecimento é o "Vakinha", que iniciou focando a aquisição coletiva de presentes, mas atualmente aceita também projetos de cunho social.

\section{As plataformas de crowdfunding brasileiras}

Como já referido no comentário metodológico, ao longo dos anos de 2012 e 2013 foi efetuada uma exploração nas plataformas de crowdfunding brasileiras para fins de 
classificação através da verificação de seu foco e modelo de atuação, conforme NESTA (2012) (Tabela 1).

Tabela 1 - Distribuição das plataformas conforme modelo de recompensa

\begin{tabular}{|l|c|}
\hline \multicolumn{1}{|c|}{ MODELO } & QUANTIDADE \\
\hline Doação & 8 \\
\hline Recompensa & 39 \\
\hline Concessão de Empréstimos & 4 \\
\hline Investimento Total & 8 \\
\hline \multicolumn{2}{|c|}{ Fonte: elaborada pelo autor. } \\
\hline
\end{tabular}

Observa-se que o modelo predominante de crowdfunding no Brasil, a ponto de somar mais que todos os demais juntos, é o modelo de recompensa, ou seja, aquele em que os doadores recebem contrapartidas dos executores do projeto, seja com citação dos nomes, ingressos, exemplares exclusivos ou diversas outras formas.

Tendo em vista a necessidade de seleção para análise (Tabela 2), e levando em conta o primeiro critério, referente à quantidade de projetos, conforme citado no comentário metodológico, foram selecionadas as plataformas "catarse.me" e "idea.me". Serão focados os objetivos destas plataformas, o formato e processo de submissão e apoio, bem como a observação e caracterização geral dos projetos disponibilizados.

Tabela 2 - Distribuição das plataformas de crowdfunding no Brasil

\begin{tabular}{|l|c|}
\hline \multicolumn{1}{|c|}{ TIPO } & QUANTIDADE \\
\hline Projetos Culturais & 18 \\
\hline Projetos Sociais & 10 \\
\hline Projetos Diversificados & 9 \\
\hline Empreendedorismo & 3 \\
\hline Software & 2 \\
\hline StartUps & 1 \\
\hline Outras Total & 16 \\
\hline \multicolumn{1}{|c|}{ T9 } \\
\hline
\end{tabular}

Fonte: elaborada pelo autor.

\subsection{Catarse.me - a maior comunidade de crowdfunding do Brasil}

O Catarse, autodenominado "a maior comunidade de crowdfunding do Brasil", foi criado em 2011 por um grupo de pessoas de estados como São Paulo, Rio de Janeiro e Rio Grande do Sul que administram o site como "um espaço de trocas entre indivíduos que, juntos, viabilizam a realização de projetos criativos". 
Através do Catarse, pessoas com ideais nas mais variadas áreas podem apresentar seus projetos para análise e apoio financeiro de todas as pessoas da Internet, cuja única tarefa será fazer um cadastro e efetuar a doação com cartão de crédito. 0 processo se inicia com o envio do projeto pelo proponente, o mesmo passa por uma curadoria cujo objetivo é, primeiramente, filtrar os projetos, para depois auxiliar o proponente a aumentar as chances de aprovação e sucesso da proposta.

Todos os projetos passam, obrigatoriamente, pela curadoria, de forma a filtrar projetos ainda em fase embrionária ou com riscos na execução. Conforme os critérios gerais, citados na plataforma, o projeto deve ser "criativo e finito", trazer "benefícios coletivos", prever "recompensas não financeiras" aos apoiadores, "não ser um projeto tipo financie minha vida ou caridade" e ter obrigatoriamente um "vídeo de apresentação" (figura 1).

Figura 1 - Como funciona o Catarse

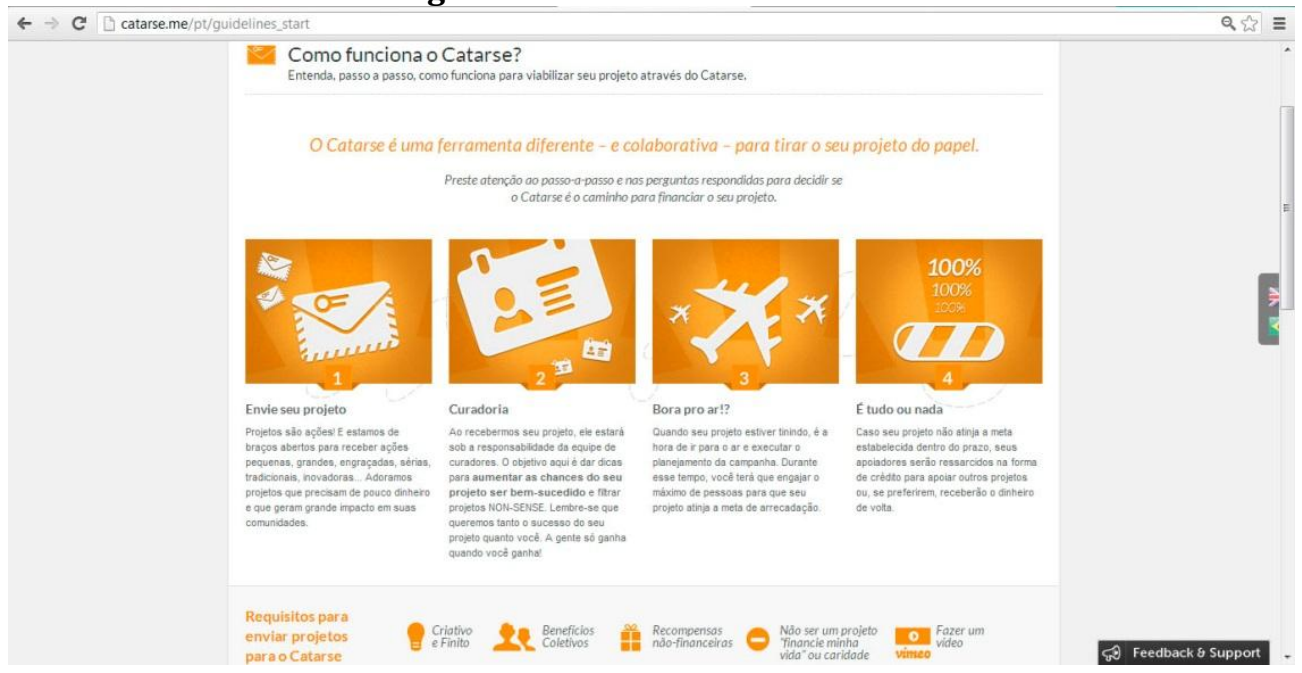

Fonte: Catarse (2013).

Isto feito, ou seja, cumpridas estas exigências e passada a etapa de curadoria, o projeto passa a ficar disponível no site da plataforma para receber apoio, com prazo para finalizar. Se atingidos os valores necessários, o proponente recebe os valores para a realização do projeto. Se não atingir a meta de captação necessária, os doadores ou recebem os valores de volta ou podem doar para outro projeto.

Todos os projetos devem ter algum tipo de recompensa prevista, ou seja, o realizador deve dar uma contrapartida aos apoiadores, seja através de citação nos créditos, envio de exemplares ou convites, ou outra forma que garanta aos internautas que contribuíram 
financeiramente para a realização e concretização da ideia uma forma de retorno sobre os valores dispendidos.

0 processo de inserção do projeto e criação de textos, imagens e vídeos de divulgação fica totalmente a cargo do proponente, a quem cabe gerar os documentos necessários, fazer o projeto circular na mídia e em redes sociais, bem como executar o projeto em caso de obtenção de todo o apoio pedido.

Este é um ponto curioso do sistema do Catarse: não há, aparentemente, nenhum tipo de controle sobre a realização do projeto e seus custos, ou seja, não fica claro de que maneira a plataforma, que intermedia a operação financeira, consegue acompanhar os gastos e dar garantia da realização do projeto. Aparentemente o sistema de crowdfunding do Catarse funciona no "fio do bigode", na confiança dentro da comunidade de apoiadores e realizadores.

Remunerado em $13 \%$ do total arrecadado para fins de manutenção do processo financeiro, que opera totalmente através de cartão de crédito, o site indicava já ter mais de 55 mil apoiadores e ter recebido mais de 72 mil apoios, ou seja, doações, arrecadando mais de 6 milhões de reais de cerca de 127 mil usuários (figura 2).

Figura 2 - Estatísticas do Catarse

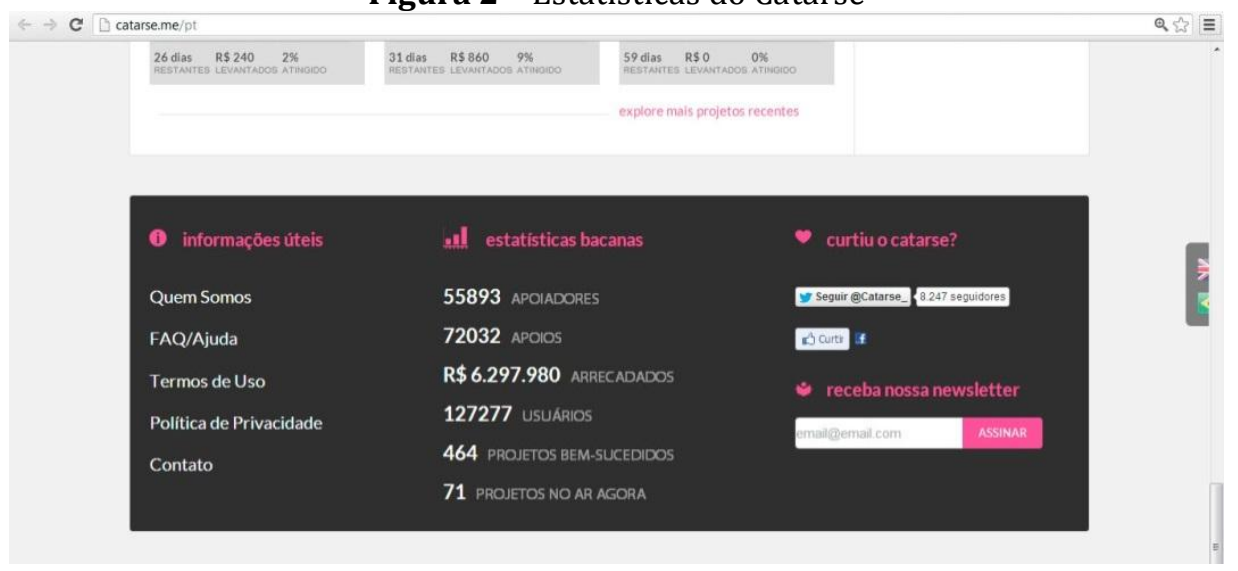

Fonte: Catarse (2013).

Nota-se que não há apoio gerencial ou estrutural para o projeto por parte do Catarse. 0 proponente do projeto recebe a consultoria inicial da curadoria para avaliação e melhorias e, depois de passado o prazo, recebe, ou não, os valores para a realização. A execução do projeto fica totalmente a cargo do proponente, que deve organizar também as recompensas conforme prometidas no projeto proposto. 
Uma observação realizada especificamente no mês de dezembro do ano de 2013 mostrou que a maioria dos projetos ficava na área cultural, abrangendo desde a produção e montagem de filmes em curta-metragem até a gravação e produção de CD’s de bandas.

Como já referimos, não fica claro como é feito o processo de acompanhamento da execução do projeto financiado, ou seja, que recursos, limites, cobranças ou penalidades o proponente de um projeto que recebeu todos os recursos terá. 0 apoio gerencial à execução não existe, nem mesmo espaço físico ou qualquer outra forma de ajuda a não ser um sistema de indicação que aproveita o potencial das redes sociais como forma de captação. Da mesma forma, não localizamos, ao longo de nossa exploração, qualquer página na plataforma que mostre os resultados dos projetos que receberam apoio.

\subsection{Idea.me - a maior plataforma de crowdfunding da América Latina}

"Idea.me" é uma plataforma de financiamento coletivo de projetos que abrange toda a América Latina, onde "artistas, designers, inventores e empreendedores" (Figura 3) podem apresentar seus projetos para financiamento pela rede, sendo a única exigência a maioridade legal devido aos trâmites financeiros.

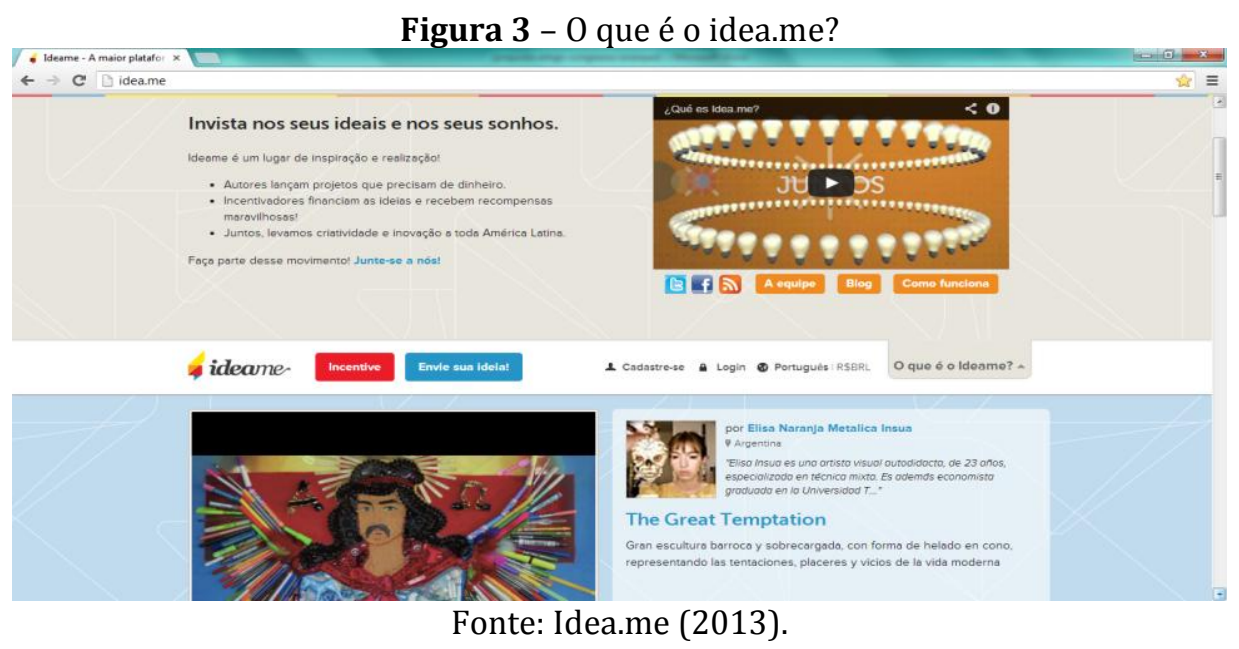

Assim como no Catarse (e demais plataformas observadas), o autor da proposta é totalmente responsável pela inserção e divulgação do seu projeto. Entretanto, ao contrário do anterior, não há dicas ou limitações quanto à duração ou caracterização do projeto, nem mesmo consultoria. 0 projeto passa por avaliação e é inserido no site dentro do prazo e com os valores solicitados pelo propositor. A página inicial do site destaca um projeto a cada dia, 
aparentemente de forma aleatória, ou seja, sem um conceito ou mesmo sem levar em conta prazo, valores ou percentual atingidos (figura 4).

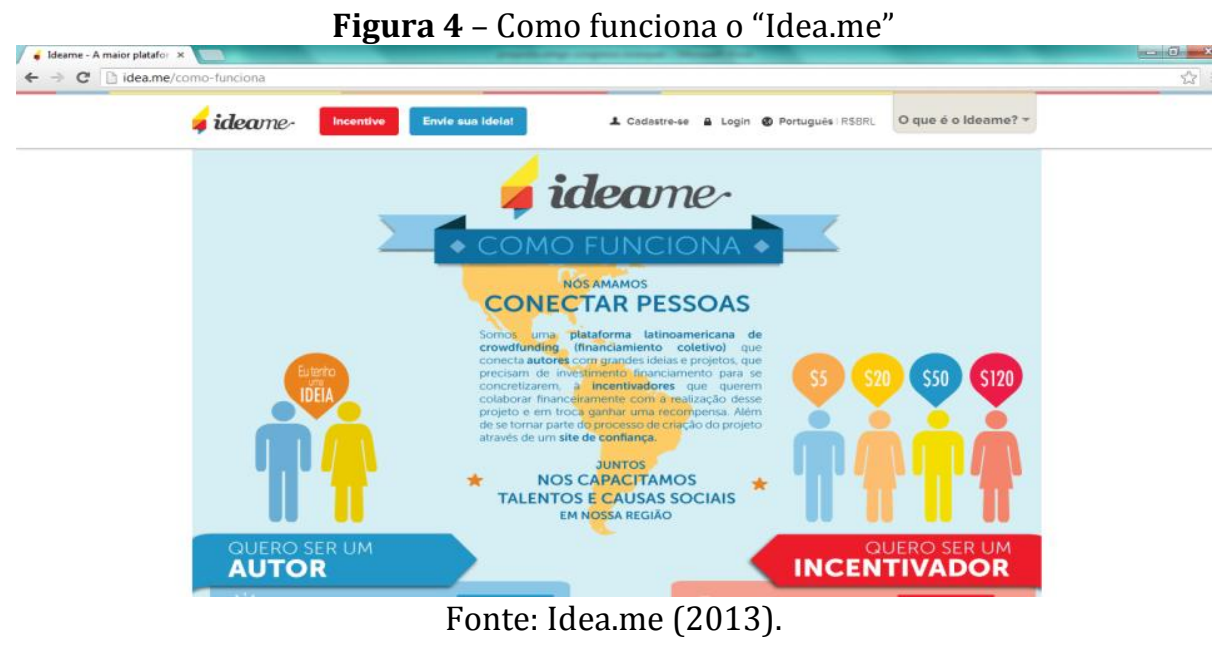

Observando os projetos disponíveis, vemos que a maioria tem foco em questões de cunho ecológico - como a alpargata biodegradável - ou culturais - como o "great temptation", em destaque na capa da semana em que efetuamos as visitas.

Os projetos são oriundos de toda a América Latina, e, da mesma forma, podem receber recursos de todos os países dessa região do continente americano . A plataforma oferta a possibilidade de filtragem dos projetos conforme o país, mas de início são apresentados todos juntos, aparentemente numa proposta de integração do continente.

O "Idea.me" se mostra como um ambiente de incentivo e apoio a ideias de cunho cultural e social, sem a necessidade de maior impacto ou mesmo sem foco no empreendedor ou no empreendedorismo, e da mesma forma sem nenhum tipo de apoio gerencial ou controle sobre os resultados além da filtragem dos projetos.

\section{Considerações finais}

Esta exploração do ambiente de financiamento coletivo disponível na Internet brasileira permitiu observar que o crowdfunding é uma realidade forte, presente e em rápido crescimento. Com novas plataformas e recursos surgindo a cada dia, mas também outras deixando de operar, o crowdfunding se mostra como uma forma nova e alternativa de captação de recursos, fora do sistema tradicional de financiamento público ou bancário, minimizando assim riscos econômicos e até mesmo facilitando o desenvolvimento de 
projetos por um público não necessariamente atendido pelo sistema tradicional, ou que não deseja estar sujeito às amarras e riscos inerentes a operações ofertadas no sistema tradicional.

Foi possível observar também que a maioria absoluta das plataformas de crowdfunding tem foco em projetos pequenos e estanques, ou seja, com começo, meio e fim determinado, que ofertam oportunidades a seus empreendedores. Não foi possível observar claramente os critérios de seleção além das informações constantes nos sites das plataformas, nem mesmo os formatos e critérios de acompanhamento e verificação das atividades e resultados obtidos. Mas é possível observar que a maioria dos projetos presentes, tanto apoiados quanto em busca de apoio, estão dentro o campo da economia criativa.

Assim, nota-se, nas plataformas observadas, que o crowdfunding oferta novos formatos de apoio e incentivo a iniciativas empreendedoras nos mais variados ramos e com os mais diversificados focos. Trata-se, sim, de uma forma de incentivo e apoio típica, nativa dos tempos de comunicação e interação sem fronteiras da Internet, cujos efeitos ainda estão começando a se fazer notar, mas que mostra potencial para mudar a relação entre produtores e consumidores em curto espaço de tempo.

\section{Referências}

BELLEFLAMME, Paul.; LAMBERT, Thomas; SCHWIENBACHER, Armin. Crowdfunding: tapping the right crowd. Journal of Business Venturing, v. 29, n. 5, p. 585-609, set. 2014.

CATARSE.ME. Como funciona o Catarse. 2013. Disponível em:

<https://www.catarse.me/pt/start>. Acesso em: 20 fev. 2014.

COCATE, Flávia Medeiros; PERNISA JÚNIOR, Carlos. Crowdfunding: estudo sobre o fenômeno virtual. Líbero, São Paulo, v. 15, n. 29, p. 135-144, jun. de 2012.

\section{FEDERAÇÃO DAS INDÚSTRIAS DO ESTADO DO RIO DE JANEIRO (FIRJAN). Mapeamento} das Indústrias Criativas no Brasil: Relatório. Rio de Janeiro: FIRJAN, 2012.

FELINTO, Erick. Crowdfunding: entre as multidões e as corporações. Revista ESPM, São Paulo, v. 9, n. 26 p. 137-150, nov.2012.

HOWE, Jeff. 0 poder das multidões: por que a força da coletividade está remodelando o futuro dos negócios. Rio de Janeiro: Elsevier, 2009. 
IDEA.ME. 0 que é o Idea.me? 2013. Disponível em: <http://idea.me>. Acesso em: 20 fev. 2014.

LÉVY, Piérre. A inteligência coletiva. São Paulo: Loyola, 2007.

MANGOLD, W. Glynn, FAULDS, David J. Social media: the new hybrid element of the promotion mix. Business Horizons, Bloomington, v. 42, n. 4, p. 357-365, 2009.

NATIONAL ENDOWMENT FOR THE ARTS (NESTA). Working the Crowd: a short guide to crowdfunding and how it can work for you. Disponível em:

<http://www.nesta.org.uk/sites/default/files/working_the_crowd.pdf $>$. Acesso em: 28 fev. 2014.

RONCOLATO, Murilo. Além das compras coletivas. 0 Estado de São Paulo, São Paulo, 13 de junho de 2011. Link - Caderno L2, p. 2.

STAKE, Robert E. Investigación con estudio de casos. Madrid: Morata, 1999.

STEINBERG, Scott. The crowdfunding bible: how to raise money for any startup, video game, or project. Self-published: Read.me, 2012.

UNITED NATIONS CONFERENCE ON TRADE AND DEVELOPMENT (UNCTAD). Relatório. 2008. Disponível em <http://unctad.org/en/Docs/dtlstict20081_en.pdf>. Acesso em: 20 fev. 2014.

YIN, Robert K. Estudo de caso: planejamento e métodos. 4. ed. Porto Alegre: Bookman, 2010.

\title{
Interactive digital media and creative economy: an exploration of the Brazilian crowdfunding platforms
}

\begin{abstract}
Internet crowdfunding, a collective financing system that allows people from all the web to contribute with a project, arises and grows fast. Even though it is a recent phenomenon, in Brazil there are more than 59 listed crowdfunding platforms with different goals and rules. Thus, this article analyzes the crowdfunding platforms in Brazil, their formats and rules, in order to observe their characteristics. The two platforms that contain the larger number of projects were selected for a deeper description and analysis.
\end{abstract}

\section{Keywords}

Crowdfunding. Interactive digital media. Projects. Creative economy. 


\section{Medios digitales participativos y economía creativa: una exploración en las plataformas de crowdfunding brasileñas}

\section{Resumen}

El Crowdfunding en Internet es un sistema de financiación colectiva que permite a las personas de todas la red efectuem contribuciones para un proyecto. A pesar del reciente, en Brasil hay más de 59 plataformas, con diferentes objetivos y métodos de trabajo. En este artículo se analizarán las plataformas de crowdfunding brasileñas, sus formatos y normas, con el fin de observar sus características y peculiaridades. Así, dos plataformas, las con mayor número de proyectos, son seleccionados para una descripción más profunda y análisis.

\section{Palabras Clave}

Crowdfunding. Financiación colectiva. Proyectos. Economía creativa.

Recebido em: 10/06/2014

Aceito em: 08/04/2015 